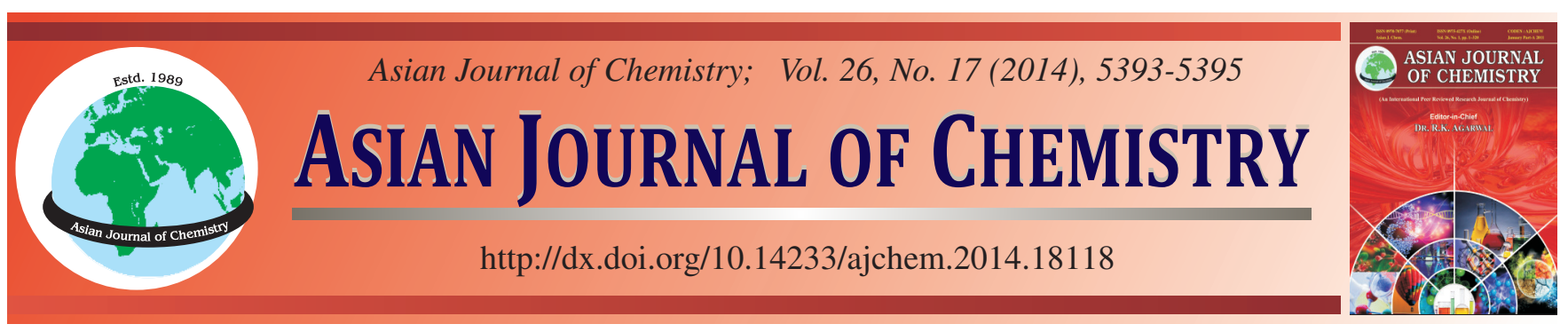

\title{
Synthesis and Application of Amino-Carboxylic Based High Performance Superplasticizer for Concrete $\dagger$
}

CHEN Xu

School of Civil Engineering, Xi'an University of Architecture and Technology, Xi'an 710055, P.R. China

Corresponding author: Fax: +86 29 82628195; Tel: +86 13152435566; E-mail: 13152435566@163.com

Aminosulfonic-based superplasticizers have been considered as a high performance superplasticizers in virtue of their superior properties. However, disadvantages such as high cost and complicated synthesis process result in limited application for these superplasticizers. In this paper, we present a novel synthesis route for amino-carboxylic-based high performance superplasticizer. In this process, carboxylic group was added to the molecules of traditional aminosulfonic-based superplasticizer by using distinctive process, feedstock and ratio. This sample has shown various advantages including low cost, high performance and the potential for large-scale application in the future.

Keywords: Sulfonation, Amino-carboxylic-based superplasticizer, High performance concrete, Compatibility with cement, Durability.

\section{INTRODUCTION}

In the field of modern concrete, plasticizer has been considered to be one of the key admixtures to improve the rheology of concrete mixture. As a key component in high performance concrete (HPC), concrete superplasticizer ${ }^{1}$ has attracted increasing attention recently ${ }^{2}$. Currently, superplasticizers in the domestic market can be divided into five categories i.e., naphthalene, melamine, aliphatics, aminosulfonics and polycarboxylate. Among these superplasticizers, the naphthalene superplasticizers have an $80 \%$ market share, while melamine, aliphatic and sulfamic acid ones are not comparable to naphthalene ones due to their limitation in cost and performance. Nevertheless, aminosulfonic-based superplasticizers ${ }^{3-5}$ have attracted considerable attention and their market share is increasing rapidly, in virtue of their excellent compatibility with the concrete, superior water reducing rate, minimized slump loss and no air entrainment.

In virtue of its prominence, various investigations have been done on the aminosulfonic-based superplasticizers. Furuhashi et al., reported concrete superplasticizers based on condensed mixture of amino-aryl sulfonic acid, phenol and formaldehyde. This superplasticizer showed good dispersion capability, as well as minimization of concrete slump loss, which makes it a perfect candidate for pumpable concrete. Since then, the study of aminosulfonic-based superplasticizer has expanded rapidly. Kawamura reported a superplasticizer based on condensed mixture of bisphenol compound, alkylamino phenylsulfonic acid and formaldehyde and this superplasticizer showed water reducing rate of 35-55\% and maintained good fluidity for $1 \mathrm{~h}$ above in the mortar mixing process. A superplasticizer based on condensed mixture of sulfanilic acid, bis $\mathrm{S}$, benzoic acid and formaldehyde is available in literature. Ishitoku presented a dispersing agent based on condensed mixture of trisphenol, sulfanilic acid and formaldehyde, while Tsuji reported a superplasticizer which is based on condensed mixture of phenol, anilinesulfonic acid, melamine and formaldehyde and capable of improving concrete fluidity. These superplasticizers presented superior water reducing rate and controlled slump loss. Feng et al. ${ }^{6}$ reported a novel aminosulfonic-based superplasticizer, aminosulfonic, based on condensation of anilinesulfonic acid, phenol and formaldehyde and conducted an investigation on its compatibility with naphthalene superplasticizers. The investigation showed that aminosulfonic-based superplasticizer is highly compatible with naphthalene superplasticizers, as well as various concrete. Moreover, it is shown that this superplasticizer has a superior water reducing rate and reasonable slump loss over time.

Likewise, a research group from Chemical Engineering Laboratory, South China University of Technology has done an investigation on the aminosulfonic-based superplasticizers. By optimizing various parameters, they developed aminosulfonic based plasticizer, which is a novel aminosulfonic-based superplasticizer, based on polycondensation of sulfanilic acid, 
phenol (heated in water solution) and formaldehyde. The aminosulfonic based plasticizer showed a water reduction rate of $25 \%$ above, less relative fluidity loss and significantly improved compression strength. However, the cost was relatively high and it's sensitive to the content. To make it worse, segregation and weeping are common for this sample.

The aminosulfonic-based superplasticizers available are limited by two factors. One factor is cost. The reactants, phenol and sodium $p$-aminobenzenesulfonate, are relatively expensive, resulting in high cost of the superplasticizers. The other factor is the sensitivity to content ${ }^{7-9}$. With low content of the plasticizers, dispersion of cement particles is ineffective and the slump loss is severe. With high content of the plasticizers, dispersion of cement particles will be over effective, which resulted in severe segregation and weeping, or even separation of slurry and water.

To overcome these issues, we present a novel synthesis method of the amino-carboxylic-based superplasticizers. This method can deliver samples with significantly lower cost and enhanced properties.

\section{EXPERIMENTAL}

\section{Mechanism}

Step-1: Sulfonation: With concentrated sulphuric acid, benzoic acid and phenol as the reactants, the sulfonation reaction was carried out at $85-95^{\circ} \mathrm{C}$. By adjusting the $\mathrm{pH}$ value to $7-8$ with $30 \%$ sodium hydroxide, sulfonated products were obtained. The reaction equation is as follow:<smiles>Oc1ccccc1</smiles><smiles>O=C(O)C1=C[C+]C=CC=C1</smiles><smiles>OC1=[C+]C=C(O)C(O)=C1</smiles><smiles>O=C(O)c1ccc(S(=O)(=O)O)cc1</smiles><smiles>O=S(=O)(O)c1ccc(O)cc1</smiles><smiles>O=C(O)C1=C[C+]=C(SO)C(O)=C1</smiles><smiles>O=[W]c1ccc(O)cc1</smiles><smiles>CC(=O)c1ccc([N+](=O)[O-])cc1</smiles>

In this equation, $\mathrm{M}$ stands for $\mathrm{Na}^{+}$.

The mass ratio of benzoic acid, phenol and sulphuric acid was 20-40:55-75:100-115 and the reaction time was 2.0 $\pm 0.5 \mathrm{~h}$.

Step-2: Polycondensation: In this reaction, water, phenol and sodium $p$-aminobenzenesulfonate were added into the products obtained from step 1 . With addition of sodium hydroxide (solid), the $\mathrm{pH}$ value of the reactants was kept at 8-10. Mean- while, the temperature was increased gradually to $75-85^{\circ} \mathrm{C}$. After that, formaldehyde was added into the reactor in dropwise within $2.0 \pm 0.5 \mathrm{~h}$ at constant temperature. Then, the temperature was increased to $80-90{ }^{\circ} \mathrm{C}$, at which polycondensation (4-6 h) took place and amino-carboxylic-based superplasticizers were obtained. The reaction equation is given in Fig. 1.

The mass ratio of sulfonated products, sodium $p$-aminobenzenesulfonate, phenol and water was 60-70:38-50:2540:230-250 and that of formaldehyde and phenol was 65$80: 25-40$. The reaction time for polycondensation reaction was $6.0 \pm 0.5 \mathrm{~h}$.

The mass ratio of each reaction was as follow: (a) Sulfonation: benzoic acid: phenol: concentrated sulphuric acid: liquid caustic soda (solid content $=30 \%$ ) = 30-35: 70-65: 100-115: 185-190, while the optimized ratio was 30:70:110: 190. (b) Polycondensation: sulfonated product (solid content = $60 \%$ ): sodium $p$-aminobenzenesulfonate: phenol: formaldehyde $($ solid content $=37 \%)=60-70: 40-50: 25-35$ : 70-75, while the optimized ratio was 65: 50: 30: 75.

Experiment 1: In this experiment, $30 \mathrm{~g}$ benzoic acid, $70 \mathrm{~g}$ phenol and $110 \mathrm{~g}$ concentrated sulphuric acid were added into a reactor, which was heated to $85^{\circ} \mathrm{C}$ and kept for $2 \mathrm{~h}$ for sulfonation reaction. The $\mathrm{pH}$ value was then altered to 7-8 with $30 \%$ sodium hydroxide solution and sulfonated products were obtained. After that, $65 \mathrm{~g}$ sulfonated product, $50 \mathrm{~g}$ sodium $p$ aminobenzenesulfonate, $30 \mathrm{~g}$ phenol and $240 \mathrm{~g}$ water were added into another reactor, which was heated to $85^{\circ} \mathrm{C}$ and the $\mathrm{pH}$ value was altered to 8-9 with sodium hydroxide solution. Then, the solution was stirred for $15 \mathrm{~min}$ and $75 \mathrm{~g}$ formaldehyde was added in dropwise within $2 \mathrm{~h}$. The solution was kept at $80^{\circ} \mathrm{C}$ for $6 \mathrm{~h}$ so that polycondensation was completed and the novel amino-carboxylic-based superplasticizer sample was obtained.

Experiment 2: In this experiment, $40 \mathrm{~g}$ benzoic acid, $60 \mathrm{~g}$ phenol and $110 \mathrm{~g}$ concentrated sulphuric acid were added into a reactor, which was heated to $85^{\circ} \mathrm{C}$ and kept for $2 \mathrm{~h}$ for sulfonation reaction. The $\mathrm{pH}$ value was then altered to 7-8 with 30 $\%$ sodium hydroxide solution and sulfonated products were obtained. After that, $70 \mathrm{~g}$ sulfonated product, $42 \mathrm{~g}$ sodium $p$ aminobenzenesulfonate, $30 \mathrm{~g}$ phenol and $240 \mathrm{~g}$ water were added into another reactor, which was heated to $85^{\circ} \mathrm{C}$ and the $\mathrm{pH}$ value was altered to 8-9 with sodium hydroxide solution. Then, the solution was stirred for $15 \mathrm{~min}$ and $72 \mathrm{~g}$ formaldehyde was added in dropwise within $2 \mathrm{~h}$. The solution was kept at $85^{\circ} \mathrm{C}$ for $6 \mathrm{~h}$ so that polycondensation was completed and the novel amino-carboxylic-based superplasticizer sample was obtained.

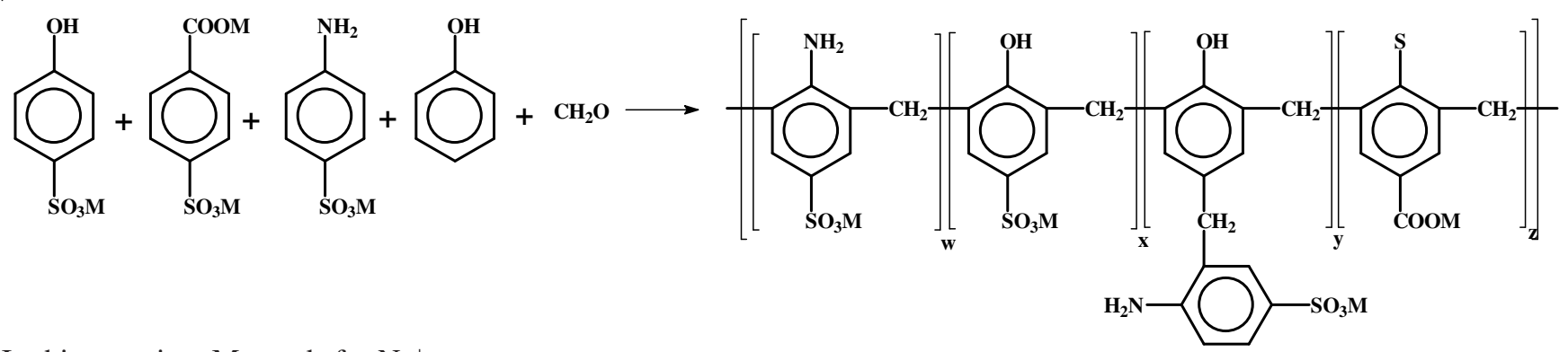

In this equation, $\mathrm{M}$ stands for $\mathrm{Na}^{+}$. 


\section{RESULTS AND DISCUSSION}

Based on the synthesis methods of traditional aminosulfonic-based superplasticizers, we presented a synthesis method in which the mixture of phenol and benzoic acid was sulfonated by concentrated sulphuric acid, followed by polycondensation reaction of the sulfonated products, phenol and sodium $p$-aminobenzenesulfonate. Without significant variation in the production technique, $-\mathrm{COOH}$ and $-\mathrm{OH}$ functional groups can be introduced into the traditional superplasticizers. As a result, higher water reduction rate, better retardation and compatibility with cement were observed in these amino-carboxylic-based superplasticizer samples. Moreover, the cost of these new superplasticizers is significantly lowered as compared to previous products.

With $0.35-0.6 \%$ (solid content) of the sample, concrete showed various superior properties. Firstly, the water reduction rate can be $25-35 \%$. Secondly, its compression strength was $130-155,135-171$ and $125-145 \%$ for 3 days, 7 days and 28 days, respectively. Then, the slump loss was low (negligible loss after $2 \mathrm{~h}$ ). Also, it showed excellent workability, low pumping resistance and no weeping or air entrainment. What's more, good exterior quality, low alkali content, no corrosion to reinforcing bars (no Cl-) and good frost resistance and anticarbonization were observed, too. Other advantages include good compatibility with various cements, excellent stability for storage ${ }^{10}$, non-toxicity and environmentally friendly (no formaldehyde).

\section{Conclusion}

The amino-carboxylic-based high performance superplasticizer presented in this report has overcome issues in the traditional aminosulfonic-based superplasticizers. This sample has shown low cost, high water reduction rate, good compatibility with cement, ease for large-scale production and environmental safety, thus great potential for industrial application in the future.

\section{REFERENCES}

1. B. Felekoglu, Resour. Conserv. Recycling, 51, 770 (2007).

2. Z.Wu and H. Lian, Concrete, 4, 10 (2000).

3. C. Li, Y. Huang and Y. Wang, J. South China Harbour Eng., 2, 19 (2008).

4. X. Cheng, J. Beijing Univ. Technol. (2010).

5. S. Assie, G. Escadeillas and V. Waller, Construct. Build. Mater, 21, 1909 (2007).

6. C. Li, N. Feng and Q. Niu, 123 (2004).

7. M. Gong, L. Chen and Y. Jiang, Coal Ash, 11 (2009).

8. H. Xiao, G. Liu and J. Xiao, China Building Mater. Sci. Technol., 26 (2008).

9. Y. Zuo, J. China Academy Building Res., (2004).

10. R.I. Malek, Z.H. Khalil, S.S. Imbaby and D.M. Roy, Cement Concr. Res., 35, 1152 (2005). 